\title{
La mediación tecnológica en el retrato
}

\section{The technological mediation in the portrait}

\author{
Marta Negre-Buso \\ Facultad de Bellas Artes de la Universidad de Barcelona. Departamento de Pintura. \\ martanegre@ub.edu
}

Recibido: 4 de septiembre de 2013

Aprobado: 24 de enero de 2014

\section{Resumen}

El retrato ha sido uno de los géneros más prolíficos en la producción artística desde la antigüedad. La fotografía ha mostrado desde sus inicios el interés por este formato, dando un impulso para su renovación dentro de las artes tradicionales. Más de cien años después, la introducción de la fotografía digital ha provocado otro cambio de paradigma. Si bien era sabido que la fotografía no era inmune a manipulaciones y trucajes, con la introducción de los medios tecnológicos el montaje pasa a ser parte de su propia ontología, situando a estas imágenes en el campo de la ficción. En este artículo se analizarán los retratos elaborados por Nancy Burson, Keith Cottingham, Aziz + Cucher, Loretta Lux y Wendy McMurdo, pioneros de la fotografía digital que, como muchos otros artistas contemporáneos, utilizan géneros y formatos propios de las artes tradicionales. Se estudiará la construcción de unas imágenes donde el referente ya no es un ser individual, sino una suma de información. La intención del texto es situar su producción dentro de un determinado contexto social, artístico y político, para ubicar unas obras que han supuesto la renovación de la representación del rostro y el cuerpo humano.

Palabras clave: fotografía digital, posthumano, arte contemporáneo, ficción.

Negre-Buso, M. (2014): La mediación tecnológica en el retrato. Arte, Individuo y Sociedad, 26(2) 337 354.

\begin{abstract}
The portrait has been one of the most prolific genres in art since antiquity. From its very outset photography has shown an interest for this format, and it has been responsible for the renewed interest in the portrait in the traditional arts. Now, more than a hundred years on, the development of digital photography has brought about another paradigm shift. While it was known that photography was not immune to various forms of manipulation and trickery, the introduction of new technological media means the montage process has become part of its own ontology, placing these images in the field of fiction. This paper looks at the portrait work of Nancy Burson, Keith Cottingham, Aziz + Cucher, Loretta Lux and Wendy McMurdo, pioneers in the use of digital photography, who, like many other contemporary artists, use genres and formats typical of the traditional arts. The paper examines the construction of images in which the reference is no longer an individual being, but rather a sum of information. The aim of the study is to place their artistic production within a given social, artistic and political context, to identify works that have meant the renewal of the depiction of the human face and body. Keywords: digital photography, posthuman, contemporary art, fiction.
\end{abstract}

Negre-Buso, M. (2014): The technological mediation in the portrait. Arte, Individuo y Sociedad, 26(2) 337-354.

Sumario: 1. Introducción, 2. Retratos digitales, 3. Conclusiones. Referencias. 
Este artículo recoge los resultados de mi investigación dentro del proyecto ALST (referencia FFI201231024), financiado por el Ministerio de Economía y Competitividad.

\section{Introducción}

En 1858, Henry Peach Robinson presentó la fotografía Fading Away (figura 1), en la que se ve a una muchacha agonizando en su lecho, acompañada por sus familiares. La imagen provocó reacciones adversas. Se consideró que era de mal gusto registrar una escena tan dramática como esta, aunque en pintura se estuviesen representando temas mucho más macabros. Pero la polémica también se hizo presente cuando el autor declaró que la joven era "una hermosa muchacha saludable de unos catorce años de edad, y la fotografía fue hecha para ver hasta dónde se la podía hacer aparecer cerca de la muerte" (Newhall, 2002, p. 76). La imagen, fruto de la copia por combinación de cinco negativos, pone de manifiesto que ya desde la aparición del medio el espectador no puede permanecer inocente delante de las fotografías. El trucaje ha sido una constante en su historia, y no un recurso propio de las tecnologías digitales. Lo que sí se puede afirmar es que actualmente la manipulación es más fácil y rápida, lo que constituye un cambio considerable en la lectura que se hace de las imágenes y en la forma de situarse delante de ellas. La diferencia substancial no radica en la propia manipulación, sino en la rapidez y la facilidad con que se puede realizar $y$, en consecuencia, en la abundancia de fotografías en las cuales resulta imposible localizar las alteraciones digitales. Tal y como anuncia Batchen, "La perspectiva es que, incapaces de discernir lo que es 'falso' de lo que es 'verdadero', los espectadores confiarán cada vez menos en la capacidad de la fotografía de ofrecer una verdad objetiva, por lo que esta perderá su poder de transmisora privilegiada de información" (Batchen, 2004, p. 313). En este sentido, Frizot viene a decir más o menos lo mismo: "El conocimiento que tendremos de todas las posibilidades de manipulación de la fotografía mediante procedimientos digitales nos la hará contemplar de otra forma, más escéptica sin duda; es decir, no le otorgaremos las dosis de confianza que solíamos otorgarle, aunque con cautela, a la fotografia" (Frizot, 1995, p. 35).

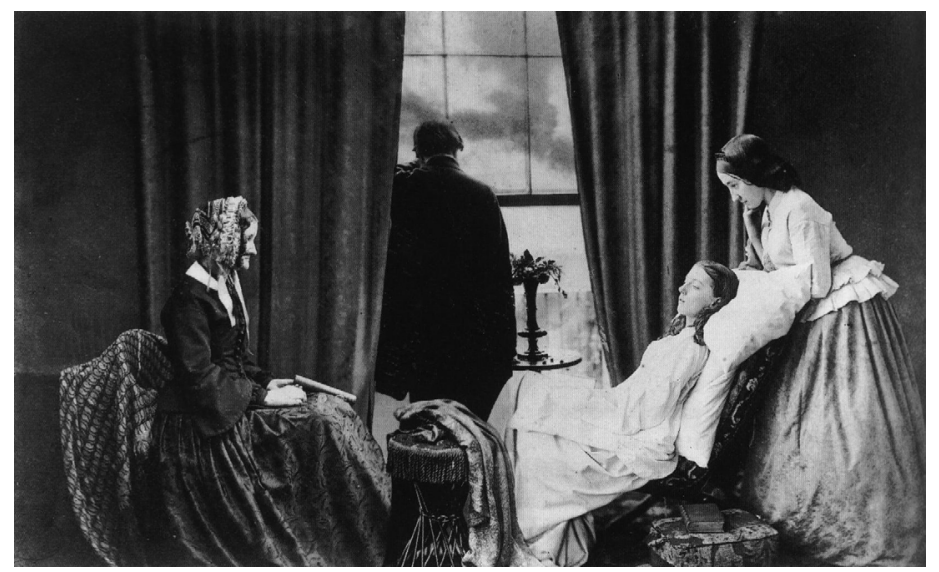

Figura 1. Henry Peach Robinson (1858). Fading Away, Positivado combinado a la albúmina. (Imagen de dominio público). 
La aparición de la imagen digital conduce hacia la pérdida de consciencia de lo que es verídico y lo que es ficticio. La palabra ficción hace referencia a aquello fingido o imaginado; por tanto, aquello que no existe. Esto plantea la pregunta de si actualmente la fotografía se aproxima más a lo fantástico e ilusorio que no a lo real. Parafraseando a Griselda Pollock, "la imagen digital no es una reproducción sino una posibilidad" (Bryant, Pollock, 2010, p. 5). En el terreno científico, la manipulación digital de imágenes es una constante en el proceso de investigación. Los avances en el campo de la tecnología digital tienen como fin generar nuevas formas de entendimiento del entorno. De hecho, el objetivo de la ciencia sigue siendo la persecución del conocimiento global para tener el control y el dominio sobre el mundo. Precisamente, las técnicas visuales han permitido, tal y como subraya Robins, "ver cosas nuevas y verlas de maneras nuevas" (Robins, 1997, p. 56). Las nuevas tecnologías han ampliado el ámbito de la visión, así como las fronteras entre lo visible y lo invisible. Esta capacidad ha llevado a Ritchin a describir como hiperfotografías las imágenes que se generan virtualmente: "Puede pensarse en ella como una fotografía que no requiere ni la simultaneidad ni la proximidad del que ve y de lo que es visto, y que considera como su mundo cualquier cosa que exista, existió, existirá o que podría llegar a existir, visible o no; en resumen, cualquier cosa que pueda sentirse o concebirse" (Robins, 1997, p. 57).

La gestión de datos en software ofrece la posibilidad de recrear imágenes virtuales de acontecimientos o situaciones que han sucedido o que podrían suceder. De esta forma las tecnologías de simulación posibilitan ver aquello que es inaccesible al ojo humano, ampliando no solo los poderes de la visión, sino también confiriendo una apariencia concreta a los fenómenos de la naturaleza. Así, el contacto directo con las cosas y su observación deja de ser la fuente de conocimiento que hasta ahora había sido. La fotografía tradicional ya no es el medio privilegiado para entender la verdad sobre el mundo. Según Weissberg, actualmente "nos movemos de una era de 'conocimiento a través de la grabación de imágenes' hacia una era de 'conocimiento a través de la simulación'” (Robins, 1997, p. 58). Tanto en el ámbito científico como en los medios de comunicación, se ha generalizado la fabricación de imágenes a partir de todo un conjunto de procedimientos absolutamente extrafotográficos. Este hecho rompe claramente la relación umbilical de este medio con el referente y arruina la teoría de la fotografía como registro puro y transparente de la realidad. Nos encontramos ante un arte de la simulación que evidencia que todo puede ser construido, subvirtiendo así las nociones tradicionales de verdad, autenticidad y originalidad.

Es preciso tener en cuenta que hay dos maneras de crear una imagen numérica: una es a partir de una imagen ya existente -un dibujo, una pintura, una fotografía o un film- que se traduce al sistema digital a través de un soporte apropiado, como puede ser un escáner, una cámara digital o un móvil; y la otra es la traducción de cálculos numéricos que generan una imagen de síntesis. La diferencia entre una forma de trabajar y la otra es que la primera continúa siendo la impresión de un objeto material, mientras que la segunda es el resultado de un programa informático donde el referente real (físico) es inexistente. Recordemos que William Henry Fox Talbot (1800-1877) definía la fotografía como "el lápiz de la naturaleza"; es decir, la forma 
en que la naturaleza se representa a sí misma: "Imprimée par la main de la Nature" (Berhardt, 2001, p. 13). De hecho, desde el siglo XIX hasta buena parte del siglo XX se ha entendido la imagen fotográfica como la reproducción de una realidad exterior; por tanto, como una representación objetiva de esta, donde la relación referencial ha sustentado este punto de vista: más de cien años después de las afirmaciones de Fox Talbot, Krauss define la fotografía como un tipo de signo, un índice, que se caracteriza por su conexión física con el referente. Si para el primero la fotografía es una reproducción exacta de la realidad, para Krauss es una huella, un indicio de esta (en ambos casos es totalmente necesaria la presencia de un original en el mundo material para su realización). Actualmente, la tecnología digital ofrece la posibilidad de crear imágenes verosímiles sin la presencia de ningún modelo. La prueba de que la acción ha sucedido delante de la cámara -ça-a-été- se desmonta. La fotografía deja de ser un memento mori, para convertirse en el simulacro de una realidad construida, tal y como describe Batchen: "Las imágenes digitales no son tanto signos de la realidad cuando signos de signos" (Batchen, 2004, p. 324).

En efecto, su propio proceso de fabricación funciona por imitación: aunque signifique una fractura con las artes figurativas tradicionales, se reapropia de sus técnicas tanto en el uso de herramientas en la interfaz del software (pinceles, lápices, etc.), como en sus resultados plásticos (técnicas collage, colores, etc.) y en la utilización de cámaras similares a las analógicas. Edmond Couchot y Norbert Hillaire señalan que la técnica digital posee una especificidad que rompe con las técnicas precedentes, a la vez que tiene la capacidad de simular y de asociarse de forma íntima con estos mismos procedimientos tradicionales (Couchot, Hillaire, 2003). Esta es la táctica utilizada por los artistas que analizaremos a continuación, con el fin de ocultar el montaje y situar sus ficciones fotográficas dentro de un género totalmente asumido por la fotografía tradicional: el retrato. Hay quien considera que, como había sucedido con la fotografía pictorialista, esta es la forma de ganarse su condición de artisticidad (Gómez, 1998). De todas formas, se puede ver que estos pioneros de la fotografía digital trabajan con los nuevos medios no solo como recurso plástico y formal, sino como base de toda su investigación. Para ellos no es preciso evidenciar la manipulación digital. Lo que pretenden es jugar con la ambigüedad entre ficción y realidad, y así cuestionar sutilmente los diferentes aspectos sociales en los que inciden. Paradójicamente, utilizan uno de los formatos donde supuestamente es más necesaria la presencia de un modelo. Hay que tener en cuenta que uno de los principales objetivos de este género ha sido intentar capturar la esencia del individuo retratado. Esta capacidad ha sido debatida y analizada frecuentemente y parece indisociable de su funcionamiento. En los retratos que generan estos artistas dicho conocimiento ya no es posible, porque detrás del semblante representado no hay una identidad por descubrir; bajo su mirada tan solo yace el vacío que deja la construcción digital. Su presencia se impone como un fantasma; o mejor dicho, como un prototipo de persona que no hace sino cuestionar la propia identidad del ser humano. 


\section{Retratos digitales}

La artista norteamericana Nancy Burson fue una de las pioneras de la manipulación digital de imágenes gracias a la colaboración de los ingenieros Richard Carling y David Kramlich, del MIT. Juntos desarrollaron un programa informático (del cual posteriormente surgió el efecto morphing) capaz de envejecer un rostro humano, y que más adelante se convirtió en una herramienta utilizada por el FBI para localizar personas desaparecidas. Burson ha tenido siempre un interés especial por la interacción entre el arte y la ciencia. Durante los años ochenta la artista generó un conjunto de retratos de individuos imaginarios a partir del morphing (técnica que sirve para crear una imagen nueva a partir de la transición de dos imágenes diferentes). En los años noventa esta tecnología mejoró considerablemente ayudando a que las imágenes resultantes fuesen mucho más reales y convincentes. Con la serie Early Composites, la artista fue la primera en generar con este procedimiento retratos artísticos de personajes ficticios. Para hacerlo se sirvió de la combinación de diferentes rostros, previamente escaneados. En estas obras aborda de forma irónica temas como la belleza, la raza o los comportamientos sociales. Por ejemplo, en First and Second Beauty Composites (First Composite: Bette Davis, Audrey Hepburn, Grace Kelly, Sophia Loren, and Marilyn Monroe. Second Composite: Jane Fonda, Jacqueline Bisset, Diane Keaton, Brooke Shields and Meryl Streep) (1982) mezcla las caras de estrellas de cine para fabricar el "ideal" femenino que anhela nuestra sociedad, ironizando así sobre la obsesión cultural por la fama, el poder y la belleza. En Mankind (oriental, caucasian and black, weighted according to current population statistics) (1983-85) parte del resultado de las estadísticas de la población del momento, que reflejan el porcentaje de ciudadanos de cada raza. El rostro que aparece es una especie de retrato robot del "habitante" del planeta a principio de los años ochenta, y por tanto, supone la antítesis de los estudios que intentan encontrar la esencia de los diferentes pueblos o etnias.

Otro ejemplo es la obra Three assassins (Lee Harvey Oswald, Sirhan Sirhan, James Earl Ray) (1982), en la que combina facciones de diferentes asesinos mostrando el arquetipo del criminal, en una clara alusión a las controvertidas investigaciones pseudocientíficas llevadas a cabo a finales del siglo XIX y principios del XX, que utilizaban estudios fisonómicos como instrumentos de control de diferentes grupos sociales. En este contexto destacan los estudios de Cesare Lombroso sobre la frenología del criminal, plasmados en su libro L'uomo delincuente (1876) (ver Zielinski, 2006), y el extenso archivo de expresiones y gestos de los dementes de $L a$ Salpêtrière, del doctor Jean-Martin Charcot. También es significativa la recolección de información fotográfica y antropométrica de cráneos realizada por Francis Galton, quien estaba interesado en instaurar lo que llamó ciencia de la eugenesia -tal como la acuñó en la obra Inquiry into the Human Faculty (1883)- como forma de catalogación y perfeccionamiento de la especie humana. Años más tarde, el régimen nazi llevó a extremos inhumanos estas ideas provocando posteriormente que esta "ciencia" fuese denostada. Para Galton, eugenesis significa "bien nacido" o "buena reproducción" (Fontcuberta, 2010, p. 68); por tanto, es evidente su similitud con las investigaciones actuales en biogenética y de ahí el interés de la ciencia por actualizarla. Otro de los personajes que utilizó la fotografía como forma de catalogación del individuo 
fue Alphonse Bertillon, de la Prefectura de Policía de París. En las láminas de sus álbumes recoge imágenes de múltiples elementos faciales para poder combinarlos $\mathrm{y}$ así encontrar la imagen de un individuo en concreto. En consecuencia, estos álbumes son precedentes claros de los actuales retratos-robot digitales, donde se consigue un rostro sin necesidad de tenerlo delante.

Dentro de Early Composites también encontramos la obra Warhead I (55\% Reagan, 45\% Brezhnev, less than 1\% each of Thatcher, Mitterrand, and Deng) (1982), donde a partir de la suma de los semblantes de los líderes políticos que controlaban el poder nuclear en la década de los ochenta, se presenta la cara del poder geopolítico y se ironiza sobre las tensiones evidentes de la guerra fría. En un contexto más popular, Baby Elvis (1989-1990) juega con las imágenes de un joven Andy Warhol y la de un joven Elvis Presley, con el fin de crear el rostro de un niño que devendría símbolo de la fama y el triunfo. Sumando dos iconos de la cultura norteamericana aparece la fisonomía de lo que podría ser el icono del niño prodigio de la cultura popular. Para terminar, en esta serie se encuentra Evolution (1984) (figura 2), en la cual la artista combina la cara de un hombre con la de un mono, dando como resultado una imagen que remite a la evolución de la especie humana.

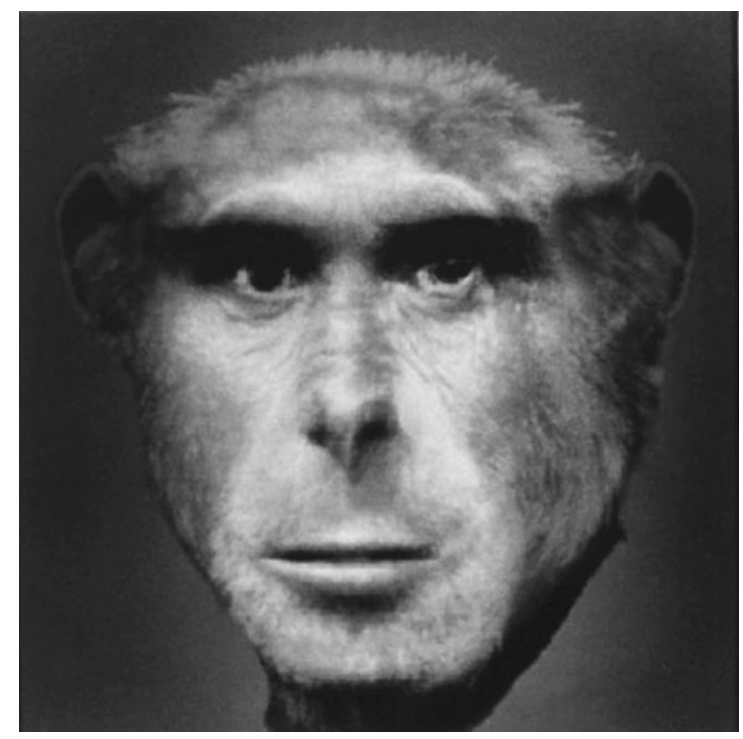

Figura 2. Nancy Burson (1984). Evolution II. Gelatina de Plata.

(Imágens de la web del Museum of Contemporary Photography. http://www.mocp.org).

Otro ejemplo de morping es $\mathrm{He} /$ She (1997), un retrato de sexualidad ambigua -o directamente andrógina- resultado de la suma de diferentes retratos de hombres y mujeres, creando una transición entre rasgos femeninos y masculinos para abordar aspectos de género e identificación sexual. Según Burson, 
Para que estas caras de hombres y mujeres fueran imparciales pensé que era importante mezclar doce rostros absolutamente diferentes. No esperaba ningún resultado concreto pero de todos modos me sorprendió comprobar que dominaban la características femeninas, si bien luego me di cuenta que lo femenino predomina siempre que se mezclan elementos masculinos y femeninos. Tal vez un motivo de este resultado se halle precisamente en el proceso -cuando se mezclan caras "corrientes" los rasgos tienden a dulcificarse, de tal modo que se leen como más femeninos. De todos modos, prefiero pensar que en una dimensión más amplia todos somos concebidos como mujeres. Para la mayoría de nosotros, en una primera mirada casi todos los niños parecen niñas. Lo femenino es primario. Nos desarrollamos a partir de ello (De Diego, 1992, p. 174).

En estos "retratos promedio" la artista confronta temas de identidad, individualidad y herencia genética. Sus fotografías adoptan una estética similar a las imágenes de Julia Margaret Cameron o la fotografía pictorialista de finales del siglo XIX, gracias a una especie de flou que hace que la imagen se desvanezca en su entorno, a la vez que se detecta un interés por la ciencia ficción. Los rostros tienen ciertas deformaciones, y muchas veces son indefinidos o monstruosos: se reconocen seres humanos, pero no es posible descifrar su procedencia ni ubicarlos en una raza, una sociedad concreta o un tiempo cronológico; tanto nos remiten al pasado como al futuro. En cierto sentido, el trabajo de Burson va a "contracorriente de las transformaciones tecnológicas" (Sand, 1996, p. 111); si bien las utiliza, también hay una voluntad de dar un giro que le sirve para regresar, o más bien, reformular la idea clásica del retrato y convertirlo en una forma de representación donde el "yo se disuelve para aparecer como un producto de interacción social" (Fontcuberta, 1997, p. 49).

Por su lado, el artista norteamericano Keith Cottingham también basa parte de su producción artística en revisar el género del retrato. Este propósito se ve claramente reflejado en la obra Fictitious Portraits (1990-92), una serie fotográfica donde aparecen imágenes de adolescentes de aire barroco. A medida que se observan, se detecta que todos los rostros conservan una gran similitud. El detalle de las fotografías y su aparente realismo choca con el aspecto de unos cuerpos que son demasiado perfectos. Esta dicotomía produce una artificialidad que pone en duda la naturaleza de los personajes retratados, los cuales resultan extrañamente inquietantes. Estas obras han sido configuradas con programas de manipulación informática a partir de dibujos anatómicos, escenas de revistas o moldes de la faz del artista. A partir del collage digital, Cottingham une las diferentes partes y añade texturas artificiales -como cabellos, piel, etc.- para obtener una representación verídica de un ser humano, que en realidad es un clon artificial de su apariencia. De forma irónica, estas imágenes aluden a la homogeneización del individuo pero también al ideal de eterna juventud y de éxito que anhela la sociedad contemporánea. En la serie Future Pre-Purposed (2000-2004) (figura 3) algunas de las fotografías están pobladas de enigmáticos sujetos que parecen realizados con plastilina. En las composiciones aparecen solos o en grupos de dos o tres, situados en espacios iluminados con una luz focal que potencia el claroscuro, dando una sensación escultórica a las figuras y a los muebles que los rodean. Sus rostros no especifican ninguna fisonomía concreta, son tan indefinidos como el mismo lugar que habitan. De hecho, sus cuerpos no son de carne y hueso sino que son una construcción digital hecha a partir de la mezcla de diferentes razas, 
edades y géneros, convirtiendo a estas criaturas en una representación genérica del ser humano. Su descontextualización invita a cuestionarse cuál es la actividad que realizan dentro de interiores vacíos y despersonalizados. Su estatismo puede ser leído como una instantánea sobre la alienación de la sociedad postindustrial, en la que el individuo reduce su actividad a la espera. En efecto, como comenta Fontcuberta, es posible que haya "más realidad en los retratos de Burson como personificaciones de la humanidad entera o en los de Cottingham como plasmación de estereotipos, que en cualquier vana instantánea. Porque como en el caso de Sherman son construcciones intelectuales que se muestran como tales" (Fontcuberta, 1997, p. 49). Para Fontcuberta el retrato ya no es un espejo del yo, sino el fruto de una construcción más mental que física, y en consecuencia no nos revela a nosotros mismos sino a nuestras invenciones. $\mathrm{Su}$ capacidad de situarse en la ficción permite a estos artistas "transmitir los valores más intangibles y frágiles del ser humano" (Fontcuberta, 1997, p. 51).

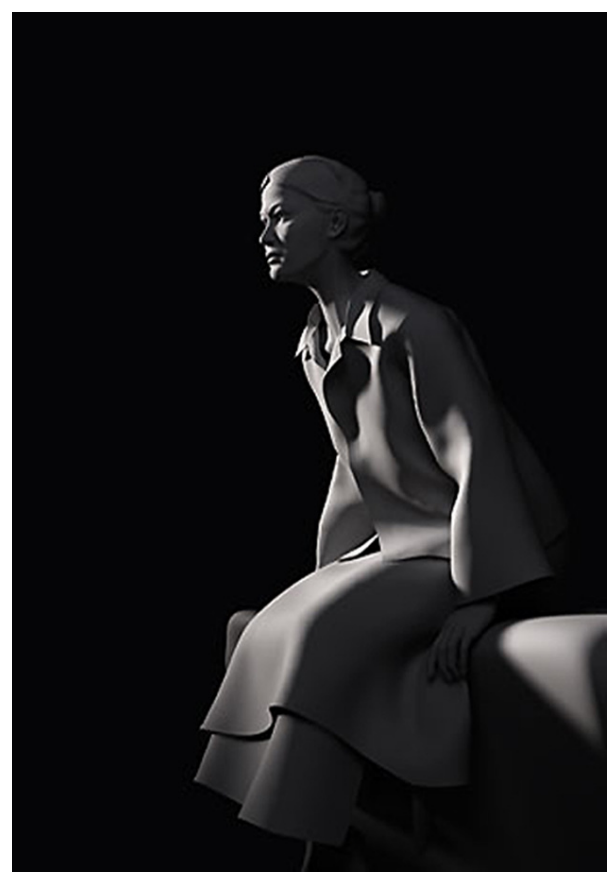

Figura 3. Keith Cottingham (2004). Portrait (waiting) de la serie Future Pre-purposed. Impresión cromogénica digital. (Imágenes de la web de Keith Cottingham: http://www.kcott.com).

Por el contrario, desde una interpretación más cercana al mundo del subconsciente, la construcción intelectual de estas fotografías es sustituida por la plasmación de una realidad psíquica, que es la que se materializa en las imágenes virtuales. Para Bryant y Pollock "La virtualidad está íntimamente relacionada a la simulación en el sentido técnico, pero parece distinto de lo imaginado o lo ficticio. Sin embargo, en su sentido no-tecnológico, la virtualidad debe entenderse en relación con la 
facultad de la imaginación y de la phantasía: el plano psíquico de la realidad, no tan perceptual, como efectiva" (Bryant, Pollock, 2010, p. 14). Este razonamiento recoge el concepto de phantasía de Freud en el sentido de lo que él llamó realidad psíquica. Tal y como apuntan Laplanche y Pontalis la realidad psíquica sería: "Lo que en el psiquismo del sujeto presenta una consistencia y una resistencia comparable a las de la realidad material; se trata fundamentalmente del deseo inconsciente y de las fantasías relacionadas" (Bryant, Pollock, 2010, p. 239).

Desde parámetros similares, la pareja artística Aziz + Cucher también aborda el tema del retrato. En su serie Dystopia (1994) muestran bustos de figuras humanas donde los orificios han sido borrados. Es decir, los agujeros de la nariz, la boca o los ojos están recubiertos de una membrana construida digitalmente que suprime los rasgos distintivos del individuo. El entorno que les rodea es un escenario descontextualizado que les otorga un aspecto más semejante al de una estatua que al de un ser humano. Sus rostros son fríos y fantasmagóricos, y las membranas son un elemento castrador y mortífero que les priva de sus capacidades sensoriales. Estas han sido mutiladas, con lo cual la obra se sitúa próxima a la ablación. En una de las imágenes se ve una pareja junta -tal vez abrazada-, pero la escena no es tierna, sino todo lo contrario. Ante esta fotografía cabe preguntarse sobre la capacidad de contacto físico que les queda: si están privados de la vista y el oído ¿también les falta el tacto? ¿y el sexo? Los orificios están anulados, lo que les aísla en su interior impidiéndoles cualquier relación con el exterior: "Estas carnes de una frialdad clínica alimentan el fantasma de un cuerpo poderoso, inaccesible al dolor, donde es legítimo preguntar sobre su sensorialidad y, aún más, sexuación" (Baqué, 2004, p. 217).

En la obra Faith, Honour and Beauty (1992), presentan fotografías de figuras humanas desnudas, con las partes genitales borradas, que sostienen diferentes objetos: mientras los hombres llevan un arma, un ordenador o un bate de béisbol, las mujeres exhiben un espejo, un bol de fruta o un bebé. Estos cuerpos blancos y asexuados sirven como denuncia a la ideología W.A.S.P. norteamericana, en la que cada sexo tiene un rol determinado dentro de una sociedad pulcra y moralmente "correcta". La estética esterilizante y profiláctica es una constante que sirve para rehuir del contacto con los propios fluidos o con el exterior. Tal como dice Baqué, Aziz + Cucher "cuestionan simultáneamente la pérdida de toda sensorialidad posible, los riesgos fascistas de prácticas eugenésicas y la aterradora "formatación" a la cual la cultura americana libra cuerpos cada vez más dóciles, cada vez más estandarizados" (Baqué, 2004, p. 217).

Aún más inquietantes son las formas orgánicas de difícil identificación de la serie Chimeras (1998) (figura 4). El título hace referencia a una criatura mitológica formada por una parte de león, una de dragón y una de cabra. De forma similar, la morfología de estas figuras parece hecha a partir del acoplamiento de diferentes miembros de un cuerpo. Estas ficciones fotográficas elaboradas digitalmente se presentan como reales porque el medio les da esta veracidad, y lo más interesante es que podrían llegar a serlo en un futuro cercano. Esto justifica el interés de los artistas por la genética y la biomedicina, a las que consideran reconfortantes y desconcertantes a la vez. Cucher, precisamente, lo ha experimentado: como portador del virus VIH ha podido probar nuevos fármacos que, según el artista, han cambiado literalmente la relación que 
tenía con su propio cuerpo y con el virus del sida: "En aquellos momentos mi cuerpo se estaba deteriorando delante de mis ojos, ahora es un cuerpo que funciona muy bien: es un cuerpo activo" (Goodeve, 1999). De hecho, esta nueva visión de la ciencia ha propiciado la concepción de un nuevo paradigma de representación que nada tiene que ver con el gusto por la abyección que predominaba en los años ochenta. Los cuerpos amorfos de Chimeras remiten a la figura de Frankenstein, pero no muestran las suturas, superando así la fase de lo mecánico. A partir del collage digital y de una estética afín a la ciencia ficción, Aziz + Cucher elaboran una metáfora de un mundo que se modifica al ritmo de los avances tecnológicos, planteando la cuestión de lo que es natural y lo que es artificial. Sus fetos no son simplemente monstruos, sino alegorías de la creación de nuevas formas de vida y de las controvertidas e inimaginables posibilidades que ofrece la biotecnología. Las obras de estos artistas se infiltran en un territorio donde lo humano y lo sintético se entremezcla, dando lugar a la figura del posthumano: una criatura que se caracteriza por ser penetrada por un entorno de artificialidad -a través de gadgets, prótesis o dispositivos- que permite y a la vez determina sus funciones. El posthumano podría ser también una tipología de cyborg. Según Haraway: "A finales del siglo XX todos somos quimeras, híbridos teorizados y fabricados de máquina y organismo; en una palabra, somos cyborgs. El cyborg es nuestra ontología, nos otorga nuestra política" (Haraway, 1995, p. 254).

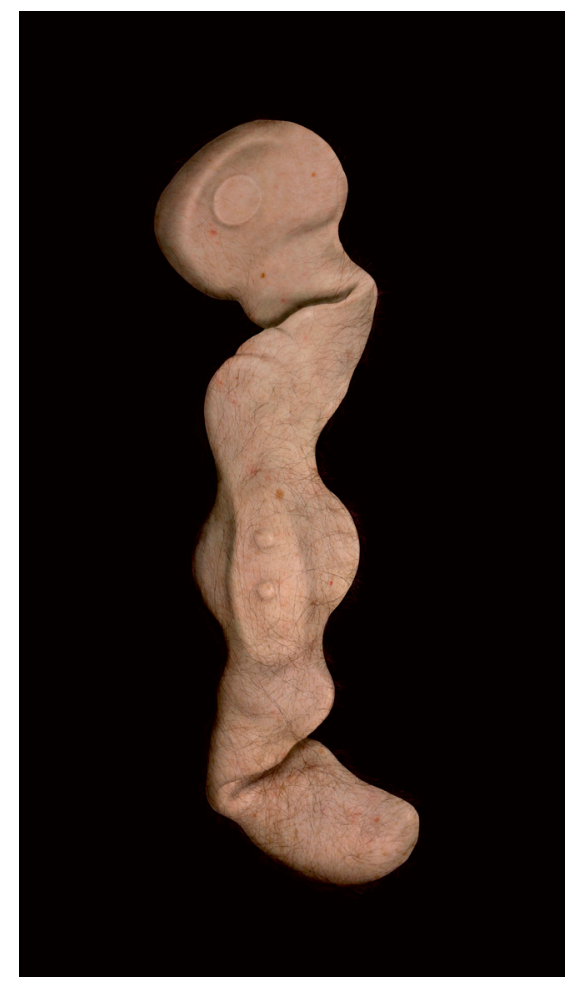

Figura 4. Aziz + Cucher (1998). Chimera \#6. C-Print.

(Imágenes de la web de Aziz + Cucher: http://www.azizcucher.net). 
Como es sabido, la capacidad del hombre de producir una realidad que antes no existía se denomina techné. Las posibilidades de la tecnología y del conocimiento facilitaron que el hombre se desprendiera de su condición original de animal, pero también es cierto que la hibridación del hombre con la máquina siempre ha provocado fascinación y horror. Múltiples novelas, fábulas y films se han referido a ello. Precisamente, Hermínio Martins plantea una analogía entre dos tendencias en la historia de la filosofía tecnocientífica y dos figuras mitológicas de la cultura occidental: Fausto y Prometeo. Según el autor, las dos vías han convivido en tensión durante diferentes periodos, si bien en la contemporaneidad se impone la tendencia fáustica que tiene por finalidad "un impulso ciego hacia el dominio y la apropiación total de la naturaleza, tanto exterior como interior al cuerpo humano" (Sibilia, 2009, 42). Esta visión ha desplazado a la tendencia prometeica, que pretendía doblegar técnicamente a la naturaleza por un "bien común", confiando en la idea de progreso para mejorar las condiciones de vida de la sociedad, desde unos límites concretos que serían respetados. Ahora el ambicioso programa de la tecnociencia ostenta el poder de modelar cualquier material o forma de vida, con el objetivo de controlar el devenir del mundo en una sociedad postcapitalista que absorbe sus conocimientos al servicio del mercado global. Dentro de este contexto, el deseo de superar la condición material del cuerpo humano se ha convertido en uno de los ejes centrales de la investigación. Su lucha por evitar el envejecimiento y en última instancia la muerte, es su principal meta. Los retoques cosméticos y la implantación de prótesis han dado paso a programas complejos de ingeniería genética, subvirtiendo, tal como considera Sibilia, "la antigua prioridad de lo orgánico sobre lo tecnológico y tratando a los seres naturales preexistentes como materia prima manipulable". Parece ser que en un futuro próximo los avances en ingeniería genética desplazarán al ser posthumano -con acoplamientos mecánicos- para dar paso a un organismo postorgánico, que funcionará con dispositivos electrónicos, digitales e injertos genéticos, dándose la posibilidad que el cuerpo desaparezca convirtiéndose en pura información. En este sentido es necesario recordar la dicotomía que observaba Haraway en la potencialidad de sus embrionarios cyborgs. Según su teoría, en un mundo cyborg estos seres pueden ser, por un lado, cuerpos al servicio del poder dominante, o por el otro "Realidades sociales y corporales vividas en las que la gente no tiene miedo de su parentesco con animales y máquinas ni de identidades permanentemente parciales ni de puntos de vista contradictorios, dando la posibilidad así a otras formas de construcción de la subjetividad que no sean las impuestas culturalmente" (Haraway, 1995, p. 263).

Los cuerpos asexuados de Faith, Honour and Beauty nos remiten a la primera vía, unos seres dóciles puestos al servicio de los poderes e instrumentos de control. Las Chimeras, en cambio, son posibilidades de otras vidas alternativas, superando la fase de lo mecánico, para convertirse en prototipos de seres postorgánicos, presagiando lo que podría ser la ingeniería genética.

Bien diferente es la propuesta de Loretta Lux. Sus retratos se centran en la representación de niños y niñas a partir de la suma de técnicas analógicas y digitales de las que resultan unas imágenes oníricas de acabado pálido y atmosférico (figura 5). De hecho, el proceso de trabajo de Lux empieza mucho antes del retoque digital. En primer lugar, fotografía a sus modelos en un plató con una iluminación clara y 
uniforme para evitar las sombras. La homogeneidad dota a la figura humana de una atemporalidad evidente. Los retratos que obtiene son escaneados y superpuestos a unos fondos sacados de archivos de imágenes o del proceso de digitalización de sus pinturas. A continuación, suprime los detalles irrelevantes al tiempo que modifica ligeramente los cuerpos de los niños. Con una mirada atenta por parte del espectador se perciben ciertas anomalías en los cuerpos de las criaturas, por ejemplo: la ropa que llevan les va estrecha, o sus cabezas están sutilmente dilatadas, así como sus brazos alargados. Cabe decir que la artista antes de dedicarse a la fotografía era pintora, por ello su obra actual tiene grandes deudas con esta técnica; de hecho, el trabajo minucioso que realiza cuando retoca las imágenes parece propio de la pintura. Este proceso, junto con la hibridación de técnicas que utiliza, nada tiene que ver con la captura del instante decisivo propio de la fotografía analógica. Ella misma asegura que utiliza la cámara como una herramienta, acercándose a la pintura desde una perspectiva diferentes: en el ordenador organiza las formas y los colores de manera similar a como lo haría una pintor delante de una tela, por eso para completar una sola imagen necesita varios meses (Tully, 2005). Su propósito es llegar a un extraño equilibrio entre la ficción y el realismo fotográfico. Son múltiples y contradictorios los adjetivos que han definido estas imágenes: inquietantes, encantadoras, perturbadoras, preciosas, horripilantes, chillonas o infantiles, entre otros. La artista busca la ambigüedad para provocar cierta reacción que sirva para que las fotografías funcionen y no dejen indiferente al espectador (Hart, 2005). Las representaciones de Lux van más allá del género del retrato: en estas fotografías no hay una intención de reconocer a un individuo concreto. Todo lo contrario, son imágenes estereotipadas, que se basan en la idealización que el adulto ha hecho de la infancia, mostrando a unos seres que pueden ser a la vez fascinantes, bellos, distantes y ausentes. El resultado es una estetización grotesca. En definitiva, son imágenes edulcoradas que se esfuerzan tanto por gustar que finalmente consiguen reacciones adversas. Precisamente esta búsqueda de lo estandarizado, junto con el acabado emblanquecido, recuerdan a la ilustración norteamericana de la década de los cincuenta o las fotografías de estudio de los años sesenta y setenta. Una estética voluntariamente intencionada que le sirve para establecer una relación irónica que se ve reforzada por el tamaño reducido de la ampliación, de unos $50 \mathrm{~cm}$ por lado. Asimismo, es fácil encontrar otros referentes en su obra, como por ejemplo la similitud con las inquietantes representaciones de niños de Philipp Otto Runge, o la afinidad de ciertas posturas, peinados y decorados con los personajes de Sandro Botticelli. Balthus es otro de los pintores de quien parece haberse influenciado. De hecho, la obra The Wanderer (2003) asemeja una revisión del cuadro The Mountain (1936) de este pintor. Otras posibles referencias son las obras de Lewis Carroll, los enigmáticos dibujos de Henry Darger, la pintura kitsch de Margaret Keane, la irónica propuesta de John Currin o la animación japonesa. En definitiva, la iconografía que muestra la artista es heredera tanto de los antiguos maestros como de la cultura contemporánea. El resultado de este cúmulo de intereses son unas delicadas imágenes dotadas de una misteriosa perfección; seres familiares que a la vez parecen misteriosos y desconocidos. La belleza y el realismo de su rostro parece que hayan sido concebidos en otro mundo. El efecto es paradójico: son demasiado reales para ser creíbles; demasiado ideales para ser reales. 


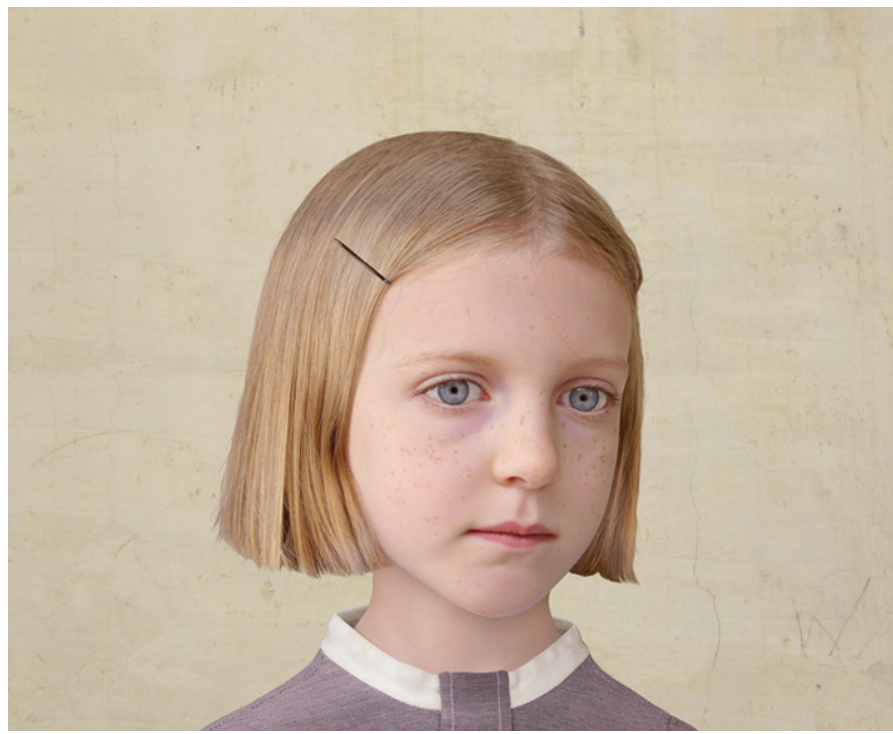

Figura 5. Loretta Lux (2006). Dorothea, fotografía color. (Imágenes de la web de Loretta Lux: http://www.lorettalux.de).

Los niños son también protagonistas en las imágenes de Wendy McMurdo, otra de las pioneras de la fotografía digital. La obra Helen, Backstage, Merlin Theatre (The Glance) (1995) muestra el encuentro fortuito de un niña con su propio doble, a quien observa de forma expectante. Esta fotografía forma parte de la serie In a Shaded Place - The Digital and the Uncanny (1995) (figura 6), donde este tipo de situaciones se repiten: los diferentes protagonistas de las imágenes se confrontan con la presencia de una o más réplicas de sí mismos. La interpretación de estas escenas puede ser leída a través de la figura del doppelgänger, palabra alemana que significa "doble", desde la acepción de "doble fantasmagórico de una persona viva". El término fue acuñado en 1796 por el escritor romántico alemán Jean Paul, quien unió los vocablos doppel ('doble') y gänger ('andante') para referirse a una criatura mítica del folclore germánico que selecciona una persona al azar para poderla observar, imitar y finalmente sustituir en la vida real sin ser descubierta por los demás. Esta figura ambigua entre lo real y lo irreal constituye una de las características que Freud reúne bajo la experiencia de lo siniestro.

Asimismo, "la repetición de lo semejante" (Freud, 2006, p. 2495) es otro factor atribuible al carácter siniestro del doble. Los personajes de las fotografías de McMurdo son niños, y este hecho no es arbitrario. El doble no es un gemelo, sino una reproducción exacta que permite verse desde el exterior. El asombro de los jóvenes delante de sí mismos remite al autorreconocimiento de su yo, momento en que el niño se descubre como individuo que está en proceso de formar su identidad. La voluntad de incidir en lo siniestro tampoco es casual. Según Freud, "Lo siniestro en las vivencias se da cuando complejos infantiles reprimidos son reanimados por una 
impresión exterior, o cuando convicciones primitivas superadas parecen hallar una nueva confirmación" (Freud, 2006, p. 2503).

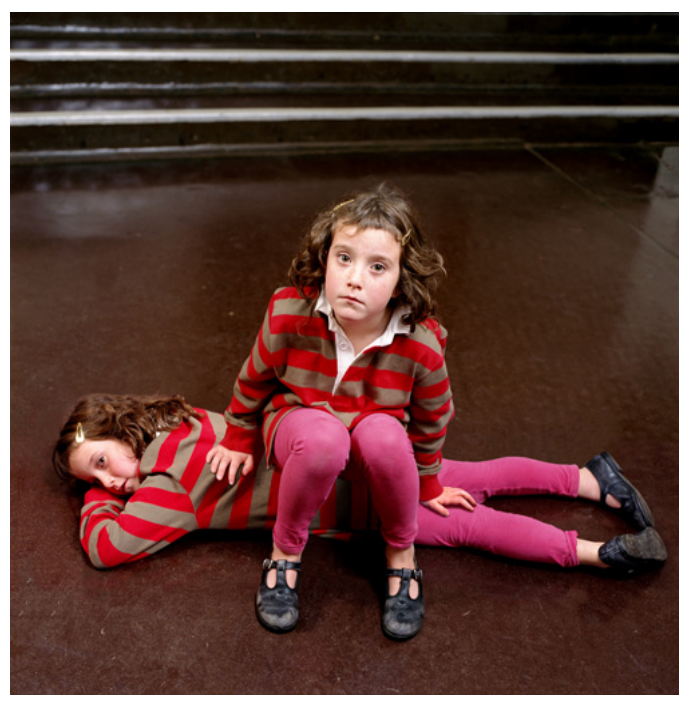

Figura 6. Wendy McMurdo (1995). Helen_Sheffield, de la serie In a shaded place, the digital and the uncanny, fotografía color. (Imágenes de wikipedia: http://en.wikipedia.org/wiki/Wendy_McMurdo).

Por tanto, es en la infancia donde se arraigan las diferentes obsesiones de cada individuo. Estas figuras repetidas parecen formar parte del sueño de un adulto en su regresión a la niñez; en definitiva, en su búsqueda por reconocer sus impulsos primitivos, o en el descubrimiento de lo que Jung llamó sombra:

La suma de todas las disposiciones psíquicas personales y colectivas, que no son vividas a causa de su incompatibilidad con la forma de vida elegida conscientemente y se constituyen en una personalidad parcial relativamente autónoma en el inconsciente con tendencias antagónicas. La sombra se comporta respecto a la consciencia como compensadora, su influencia, pues, puede ser tanto negativa como positiva. Como figura onírica la sombra tiene el mismo sexo que el que sueña. Como parte del inconsciente personal, la sombra pertenece al Yo; pero como arquetipo del "adversario" pertenece al inconsciente colectivo. [...] La omisión y la supresión de la sombra, así como la identificación del Yo con ella, puede llevar a desdoblamientos peligrosos. Puesto que la sombra está próxima al mundo de los instintos, es indispensable tenerla en cuenta constantemente (Jung, 2007, p. 482).

Así pues, la sombra es el aspecto inconsciente de la personalidad, donde se hallan los rasgos y actitudes que el yo consciente no reconoce, y al mismo tiempo 
tiene relación con el arquetipo. Para Jung, este concepto se deriva de la observación repetida de mitos y cuentos de la literatura universal que contienen en todas partes motivos similares, y que también se pueden encontrar en fantasías, sueños, delirios e imaginaciones de los individuos actuales, a las que el autor llamó representaciones arquetípicas, entre las cuales se encontraría el mito del doppelgänger. Curiosamente, En la sombra es el título de la serie fotográfica de McMurdo.

Por otro lado, el carácter clónico de los niños hace también referencia a los avances en biotecnología, en que el doble puede ser fruto tanto de las innovaciones robóticas, como de las investigaciones genéticas. En el proyecto My Real Baby (2009), este interés es aún más evidente. La escenas fotográficas muestran personas junto con robots interactivos de diferentes lugares del mundo a los cuales ha añadido órganos, como ojos y pestañas, para humanizar su aspecto. Este interés por el conocimiento es evidente en otras series como Science Museum Projects, donde los niños se pasean por museos de historia y ciencias naturales. La teatralidad de las escenas evoca cierta artificialidad que convierte en extraño lo familiar; otra característica que Freud atribuyó a lo siniestro. Quizás el aspecto que más desconcierta es el reconocerse en el papel de estos niños que se muestras atentos, vigilantes, preocupados y a veces absortos. Su aparente inocencia no los hace ajenos al mundo que les rodea y a un futuro tecnificado del que pronto serán agentes activos. Como dice McMurdon "En ninguna parte se ve este futurno expresado más claramente que en la imagen del niño" (McMurdon, 2010, p. 76).

\section{Conclusiones}

Los artistas tratados trabajan con el collage digital que, a diferencia del collage tradicional, esconde su estructura interna, velando la unión de las diferentes piezas con la finalidad de aparentar escenas verdaderas. Esta estrategia hace que se inscriban en una estética del simulacro y, por tanto, basen su producción en la imitación de la realidad. Hasta ahora, la fotografía -aunque se la considerara una interpretación del mundo- siempre partía de alguna cosa preexistente. Con las imágenes elaboradas a partir de sistemas de síntesis ya no es indispensable la conexión física entre la placa sensible y el mundo exterior, diluyéndose así su cualidad indexal. De todas formas, en los trabajos de los artistas analizados hay una voluntad de crear representaciones verosímiles, y para hacerlo no tienen otra opción que acercarse al entorno real y copiarlo. Este es el único enlace que se puede establecer entre imagen y referente. En definitiva, el índice como huella física desaparece; en sus obras lo que permanece es un índice conceptual, un cúmulo de estratos de conocimiento que hacen posible la creación de una imagen genérica a partir de un modelo común: el rostro. La intención es que los retratos ficticios que elaboran sean síntomas del estado actual del ser humano en relación al mundo que él mismo ha ido construyendo: Lux nos remite al gusto por el kitsch introducido en los hogares como estética dominante; McMurdo propone una visión psicológica desde la figura del doble, y Cottingham, Burson y Aziz + Cucher hablan de la hibridación del hombre con lo tecnológico y de los debates éticos sobre biomedicina y clonación en un mundo condicionado por la ciencia.

En sus representaciones invierten la lógica de lo que se suele conocer como 
retrato, entendiendo este género como paradigma de la representación más íntima y directa del individuo. Paradójicamente, esto se pone en duda: en las facciones de los seres que aparecen en las imágenes no se percibe ninguna calidad descriptiva ni de reconocimiento, sino que por el contrario, estas figuras evocan a las esculturas clásicas griegas y su ideal de belleza homogeneizado. La carencia de rasgos determinados las convierte en formas genéricas y estandarizadas, y posiblemente sea esta su voluntad: reflejar una cultura obsesionada por conseguir un canon de belleza ideal que rehúye, como si no existiera, el inevitable envejecimiento y la muerte. De hecho, para hablar de un mundo fascinado por la tecnología, qué mejor que hacerlo con sus propios medios.

Por otro lado, estos artistas infiltran sus collages digitales en un espacio político y estético determinado para revisarlo desde su interior. Poivert considera que estas imágenes híbridas, que pretenden constituirse como nuevos artefactos iconográficos, imitan dentro de un fetichismo técnico las estrategias vanguardistas para así mantener la supervivencia del aparato crítico del lenguaje fotográfico. Un lenguaje del que ellas mismas constituyen el objeto de su obsolescencia (Poivert, 2002). Para José Luis Brea la potencia político-subversiva de la fotografía -sobretodo de la fotografía digital- recae en su idoneidad para desmantelar el orden de la representación: su capacidad para fusionar los recursos de la apropiación y del montaje, y su facultad para fragmentar y recomponer le permite desarrollar nuevas posibilidades narrativas y elaborar "imágenes críticas" del mundo. La fotografía no simplemente "representa" lo real, sino que crea imágenes que desvelan la estructura oculta de su organización. (Brea, 1997).

La actualización del collage facilita el reciclaje de imágenes y la confección de representaciones totalmente nuevas, desencadenando uno de los cambios más significativos en la concepción de la fotografía. Ahora ya no hay una captura total de la imagen, sino una fabricación de esta a partir de una serie de parcelas que pueden ser modificadas sucesivamente durante un largo periodo de tiempo. De aquí viene la analogía de la imagen digital con la pintura, que según Fontcuberta son, en esencia, idénticas; lo único que varía son los procedimientos técnicos empleados. Por el contrario, considera que la fotografía analógica y la digital tienen pocas cosas en común, ya que la primera tiende a significar fenómenos, mientras que la última, conceptos (Fontcuberta, 2010). Para Brea, el collage permite introducir un nuevo tiempo en la imagen fotográfica, una especie de segundo obturador que es capaz de ampliar el tiempo de la captura en el tiempo de la postproducción. Es decir, que con la digitalización de las imágenes se exploran las capacidades del collage, se disimulan las costuras y se reconstruye así un nuevo espacio de pictorialidad. Brea sugiere que este hecho expande el inconsciente óptico teorizado por Benjamin, ampliando de esta manera la capacidad narrativa de la imagen fotográfica. Un inconsciente óptico que difiere de la concepción que Rosalind Krauss propone. Para ella, el espacio fotográfico está estructurado como lenguaje, equiparándolo así al inconsciente lacaniano, que puede ser susceptible de psicoanálisis. Benjamin, en cambio, hacía referencia a la capacidad de la cámara y del proceso fotográfico para aprehender en su inconsciencia todo aquello que el ojo consciente, educado en el dominio de la representación, le resulta inaprensible. Las técnicas digitales expanden estas 
posibilidades, convirtiéndose en la característica básica de lo que Brea denomina el campo postfotográfico: "La fotografía se ha vuelto narrativa, a la vez que su tiempo de exposición se ha expandido más allá del instante abstracto de la captura" (Brea, 2002, p. 28). Los trabajos de Burson, Cottingham, Aziz + Cucher, Lux y McMurdo utilizan todos los recursos disponibles para propiciar este tiempo narrativo más dilatado, que les permite dar cuenta, dentro de la imagen-cuadro, del funcionamiento de una sociedad sumida en el capitalismo cognitivo, sirviéndose de todo ello para explorar nuevas posibilidades en la representación.

\section{Referencias}

Baqué, D. (1999). Photographie plasticienne, l'extrême contemporain. París: Éditions du regard.

Batchen, G. (2002). "Ectoplasma. La fotografia en la era digital". En Ribalta, J. (ed.). Efecto Real. Debates posmodernos sobre fotografía. Barcelona: Gustavo Gili; 313-334.

Bernhardt, U. (2001). Le regard imparfait. Réalité et distance en prohotographie. París: L'Harmattan.

Barthes, R. (1989). La cámara Lúcida. Barcelona: Paidós Comunicación.

Brea, J. L. (2002). La era postmedia. Acción comunicativa, prácticas (post)artísticas $y$ dispositivos neomediales. Salamanca: Consorcio Salamanca / Centro de Arte de Salamanca.

Brea, J. L. (1997) El inconsciente óptico y el segundo obturador. La fotografia en la era de su computerización. [consult. 02-08-2013]. Disponible en <URL: http:// aleph-arts.org/pens/ics.html

Bryant, A.; Pollock, G. (2010). Digital and other virtualities. Renegotiations the image. Nueva York: I. B. Tauris.

De Diego, E. (1992). El andrógino sexuado. Eternos ideales, nuevas estrategias de género. Madrid: La balsa de la Medusa.

Fontcuberta, J. (2010). La Cámara de Pandora. La fotografi@ después de la fotografia. Barcelona: Gustavo Gili.

Fontcuberta, J. (1997). El beso de Judas. Fotografia y verdad. Barcelona: Gustavo Gili.

Freud, S. (2006). Obras completas (1916-1924). Vol. 7. Madrid: Biblioteca nueva.

Frizot, M. (1995). “Qui a peur de la lumière?". En Frizot, M. (et al). Art-Photographie numérique. Aix-en-Provence: Cypres - École d'art d'Aix-en-Provence; 18-35

Gómez, J. (1998). Imagen digital: lecturas híbrida. [consult. 02-08-2013]. Disponible en <URL: http://pendientedemigracion.ucm.es/info/univfoto/num1/pdf/hibridas. pdf $>$

Goodeve, T. N. (1999). These are the forms that we live with. [consult. 02-08-2013]. Disponible en <URL: http://www.azizcucher.net/critical-text/these-are-the-formsthat-we-live-with-reprinted-in-nature-edited-by-jeffrey-kastner-2012

Haraway, D. J. (1995). Ciencia, cyborgs y mujeres. La reinvención de la naturaleza. Madrid: Cátedra.

Jung, C. G. (2007). Recuerdo, sueños, pensamientos. Barral: Seix Barral. 
Krauss, R. (1997). El inconsciente óptico. Madrid: Tecnos.

Krauss, R. (2002). Lo fotográfico. Por una teoría de los desplazamientos. Barcelona: Gustavo Gili.

McMurdo, W. (2010). "Un futuro sin escribir". En Éxit. 40. Madrid; 74-81.

Newhall, B. (2002). Historia de la fotografia. Barcelona: Gustavo Gili.

Poivert, M. (2002). La photographie contemporaine. Paris: Flammarion.

Robins, K. (1997). “¿Nos seguirá conmoviendo una fotografía?”. En Lister, M. (Ed.). La imagen fotográfica en la cultura digital. Barcelona: Paidós; 49-75.

Sand, M. (1996) "Nancy-Burson: volte-face". En Fontcuberta, J. (Ed). Réels, fictions virtual. Recontre Internationale de la photographie. Arles: Actes du Sud; 110121.

Sibilia, P. (2009). El hombre postorgánico. Cuerpo, subjetividad y tecnologías digitales. Buenos Aires: Fondo de Cultura Económica.

Tully, N. (2005). "Carefully Composed Inconsistency". En The New York Sun. [consult. 02-08-2013]. Disponible en $<$ URL:

http://www.nysun.com/arts/carefully-composed-inconsistency/13734/

Zielinski, S. (2006). Deep Time of the Media. Massachusetts: Massachusetts Institute of Technology. 